\title{
HISTORICIDAD, REALISMO Y VERDAD
}

\author{
Carlos Miguel Gómez
}

\begin{abstract}
This paper argues that the historical character of our knowledge is compatible with both ontological and epistemological realism. The first part critically analyses the thesis according to which the situated nature of our cognitive practices implies that they do not refer to an extra-linguistic reality. The second section explores the claim that realism is a necessary presupposition of our communicative practices and the final part outlines the principles of a pluralist realism.
\end{abstract}

Keywords: Hermeneutical realism; anti-realism; Nietzsche; interpretation; knowledge.

\section{Introducción}

Una de las tendencias más interesantes y prometedoras de la filosofía en las últimas décadas consiste en la búsqueda de nuevos modelos de realismo, capaces de reconocer el carácter histórico y culturalmente situado de nuestros modos de conocer, sin concluir de allí que nuestros esquemas conceptuales, nuestro lenguaje y nuestras prácticas cognitivas son completamente arbitrarias con respecto a la realidad $\mathrm{y}$, antes que referirse a ella, la construyen. Esta búsqueda, que une a filósofos analíticos y continentales, debe enfrentar el reto de mostrar que el pluralismo epistemológico es compatible con el realismo. ${ }^{1}$ Esto implica explicar de qué modo nuestros esquemas conceptuales y prácticas discursivas locales, aunque son cambiantes, culturalmente situadas y políticamente interesadas, sólo pueden funcionar porque son formas de estar en contacto, conocer y actuar sobre la realidad, la cual tiene un modo de ser independiente de nuestras representaciones; si bien no es posible aspirar a un modo único, total o definitivo de dar cuanta de ella. Este trabajo hace parte de esta búsqueda, la cual tiene implicaciones no sólo para todas las áreas de la filosofía, sino para la vida cotidiana en las sociedades plurales del mundo contemporáneo.

La tesis que procuraré explorar y defender es que a partir de la constatación de la historicidad y pluralidad de nuestros modos de conocer no se puede concluir que estos son arbitrarios con respecto al mundo, ni que la realidad sea enteramente construida por nuestros esquemas conceptuales y prácticas discursivas. Ni el modo de ser de la realidad es irrelevante para la verdad o falsedad de lo que decimos y podemos crear con ella, ni es meramente el resultado de la proyección de las categorías y estructuras propias de nuestros modos de conocer. Por el contrario, la diversidad de nuestras prácticas y modos de conocer sólo es posible porque, lejos de ser una barrera que nos separa de la realidad, estos representan una forma de estar abiertos a ella,

Principia 21(1): 77-98 (2017).

Published by NEL — Epistemology and Logic Research Group, Federal University of Santa Catarina (UFSC), Brazil. 
y no pueden funcionar si la realidad misma no es adecuadamente captada en los aspectos que son relevantes para los propósitos y necesidades específicos que animan nuestro conocimiento en cada caso. El carácter histórico y perspectivo de nuestras prácticas epistémicas y universos simbólicos no excluye que estos puedan ser verdaderos con respecto al modo de ser de lo real, sino que por el contario constituye el modo de ser de la verdad.

\section{El problema de la historicidad de la verdad y su desenlace en el anti-realismo radical}

\subsection{El axioma hermenéutico como problematización del conocimiento y la verdad}

El surgimiento, intensificado desde la segunda mitad del siglo XIX, de lo que Wilhelm Dilthey denominó "conciencia histórica" representó uno de los más grandes golpes al modelo fundacionalista del conocimiento, en tanto que cuestionó la posibilidad de alcanzar un saber sobre el mundo cuya verdad pudiera ser asegurada apelando a principios absolutos y universales. El escepticismo radical parecía ser la consecuencia inevitable de la constatación del permanente e indisoluble cambio y conflicto entre diferentes sistemas metafísicos, cada uno de los cuales, a la vez que pretendía ser universalmente verdadero, contradecía y era contradicho por los demás (Dilthey 1974; 1978).

Con su "crítica de la razón histórica", Dilthey intentó salirle al paso a este escepticismo, procurando descubrir las leyes y las condiciones por medio de las cuales las visiones de mundo (Weltanschauungen), que pare él pueden clasificarse en tres grandes tipos (Naturalismo, Idealismo de la Libertad e Idealismo Objetivo), son constituidas como expresiones de los procesos psicológicos y de la vida histórica de un grupo humano (1974, p.41). De este modo, parecía posible reintegrar la diversidad en apariencia inconmensurable de los sistemas metafísicos en la totalidad mayor del proceso histórico.

Pero, esta solución mantiene abierta la pregunta acerca del valor cognitivo de las diferentes visiones de mundo, si estas son en última instancia la sistematización de una toma de posición emocional ante el mundo, la cual se encuentra estrechamente vinculada con la situación histórica de cada pueblo. En este sentido, el surgimiento de la conciencia histórica equivale no sólo al reconocimiento de que no tenemos un acceso directo y privilegiado a la realidad tal cual es en sí misma, independiente de nuestros modos de conocerla y actuar interesadamente en ella, sino ante todo de que no es posible ya restablecer la objetividad de nuestra experiencia y conocimiento del mundo apelando a categorías universales de constitución de los mismos. Pero, ¿qué 
todo conocimiento sea situado, es decir, que no sea posible el conocimiento absoluto, implica que no hay conocimiento en absoluto - o que este es algo tan diferente de lo que solíamos creer que sólo podemos llamarlo así por costumbre?

Sin duda, es posible sacar conclusiones diferentes e incompatibles a partir del "axioma hermenéutico" (Wachterhauser 1994, p.1, p.148) — en el cual concuerdan gran parte de filósofos contemporáneos - , según el cual toda realidad, para los seres humanos, es siempre interpretada. Lo que significa existir, lo que cuenta como un objeto y, en general, lo que significa conocer, no puede ser desligado de los esquemas conceptuales, practicas sociales, sistemas de valores y creencias que constituyen el horizonte desde el cual captamos y organizamos lo real (cf. Putnam 1981, p.49ss). Sólo es posible referirse a objetos haciendo uso del vocabulario y equipo conceptual propio de un sistema de representación, y todos estos sistemas incluyen los valores, intereses y puntos de vista de una cultura y un tiempo particulares. No hay un punto de vista absoluto, desligado de toda situación histórica, desde el cual el mundo pueda ser captado tal cual es en sí mismo. ¿Pero significa esto que todo lo que hacemos es "inventar descripciones del mundo que son útiles" (Rorty 1991, p.24) pero no representan el modo como es el mundo? Aquí se dividen las aguas en la interpretación del axioma hermenéutico.

Los que optan por una respuesta afirmativa a esta pregunta enfatizan la imposibilidad de separar el mundo de las "versiones de mundo". Pues "cuando desechamos como capas de convención todas las diferencias en los modos de describir [el mundo] (...) la cebolla es pelada hasta su núcleo vacío". (Goodman 1978, p.118) Dado que no podemos describir, ni aún imaginar (ipor definición!), cómo es el mundo independientemente de cualquier forma de conceptualizarlo, "estamos confinados a nuestras maneras de describir cualquier cosa que sea descrita. Nuestro universo, para hablar de algún modo, está hecho de estos modos de descripción más que de un mundo" (Goodman 1978, p.3).

iEstamos confinados a nuestros sistemas conceptuales, prácticas discursivas y universos simbólicos! (A la Berkeley, intentar pensar cómo sería el mundo "aparte de todos los marcos de referencia" es ya conceptualizarlo desde alguno. No podemos pararnos por fuera de nuestro lenguaje para examinar si los que decimos corresponde o no con una realidad extralingüística. i¿Qué mejor demostración puede ofrecerse de que "existir es ser representado"?! — Argumento por asfixia —).

\subsection{Nietzsche, las figuras de Chladni y la posibilidad de la metáfora}

El ensayo de juventud de Nietzsche titulado "Sobre verdad y mentira en sentido extra moral" escrito originalmente en 1873 , pero publicado hasta 1896, ha ejercido una influencia decisiva para inclinar la balanza del dilema hermenéutico hacia el extremo de lo que denominaré una filosofía de la desconexión. Si bien Nietzsche abandonó 
los elementos centrales de esta crítica inicial a la verdad y en su obra de madurez muestra un compromiso radical con "sacrificar todos los deseos a la verdad, a toda la verdad" (1997, p.36), ${ }^{2}$ muchos de quienes se proclaman sus herederos han celebrado y explorado las consecuencias de esta posición inicial que se basa en las siguientes ideas: (1) El intelecto y el conocimiento cumplen una función meramente adaptativa, orientada a garantizar la sobrevivencia de los individuos, la cual nada tiene que ver con la verdad; (2) la relación entre lenguaje y mundo es totalmente arbitraria, porque se trata de "esferas" radicalmente distintas; y (3) los conceptos son "invenciones", "metáforas" que proyectan "antropomórficamente" orden y estructura donde no lo hay. Consideremos brevemente cada una de estas ideas.

(1) En una carta a William Graham, fechada el 3 de julio de 1881, Charles Darwin expresa una preocupación que surge espontáneamente y afecta a quienes identifican la evolución con el naturalismo: ${ }^{3}$

Siempre surge en mí la horrible duda acerca de si las convicciones de la mente de un hombre, la cual se ha desarrollado a partir de la mente de animales inferiores, tienen algún valor o pueden ser confiables. ¿Confiaría alguien en las convicciones de la mente de un mono, si es que hay convicción alguna en tal mente? (citado por Plantinga 2011, p.316).

Si nuestro intelecto es simplemente un medio de conservación de los individuos que carecen, "en la lucha por la existencia, de cuernos, o de la afilada dentadura del animal de rapiña" (Nietzsche 1990, p.18), ¿por qué habríamos de pensar que tienen la capacidad de captar y representar adecuadamente el modo como es la realidad? Ciertamente, la verdad de las creencias no es necesaria para garantizar la sobrevivencia. Es suficiente con responder adecuadamente (evitando el peligro, buscando las ventajas alimenticias y reproductivas) ante estímulos cuya naturaleza, si es que tienen alguna, permanece siempre inaccesible para la mente, la cual, como veremos, sólo "finge" (miente, en sentido extramoral) saber cómo es el mundo.

Así, nuestro aparato cognitivo no está "diseñado" para el conocimiento de "la verdad" sino para la preservación de la especie y el control del mundo. Claramente, la noción de verdad que aquí está en juego, y que no puede identificarse con la utilidad para la sobrevivencia, es la que la tradición filosófica occidental ha buscado desde los griegos y que se entendió como una relación de adecuación isomórfica entre nuestros conceptos y la realidad. Para Nietzsche se trata siempre de captar "«La cosa en sí» (Esto sería la verdad pura)" (1990, p.22).

(2) ¿Qué tipo de relación se da entonces entre el intelecto y el lenguaje y el mundo? Las palabras son la "reproducción en sonidos de un impulso nervioso" (Nietzsche 1990, p.21). Esto significa que no es posible saber nada, a partir del impulso, de la causa fuera de nosotros que lo ha producido. Ni siquiera podemos inferir su existencia. No se trata sólo de que nuestros conceptos y palabras sean incapaces de captar "la 
esencia" de las cosas, o sus propiedades intrínsecas (Nietzsche 1990, pp.22-23), sino que las categorías humanas son maneras totalmente arbitrarias de dividir y clasificar lo real, las cuales son impuestas sobre la experiencia, que carece de unidad y es puro flujo. Del impulso nervioso se da un brinco a la formación de imágenes y de aquí, nuevamente, se da un paso a la formación de sonidos (palabras) vinculados a ellas. Dado que estos "brincos" de una esfera a otra no son ni necesarios ni están motivados por el modo como son las cosas o por la capacidad del intelecto de captar adecuadamente el mundo, Nietzsche los asocia con un modo de "conducta estética". Así, las palabras son "metáforas" de las imágenes mentales que a su vez son "metáforas" de los impulsos nervios (1990, p.22, p.29; 2000, p.501).

Esta tesis de la completa arbitrariedad de nuestros conceptos y palabras con respecto al mundo refuerza la visión evolucionista del conocimiento a la que nos referimos antes, pero se basa sobre todo en la idea según la cual la idea tradicional de verdad comprendida como adaequatio rei et intellectus, es insostenible porque el intelecto y el mundo son esferas completamente distintas (Nietzsche 1990, p.22, p.30). ¿Cómo podría una imagen mental o un sonido captar, representar adecuadamente, mostrar la naturaleza interna de una entidad material si ambos elementos de la relación de "correspondencia" tienen un modo de ser absolutamente heterogéneo? Ciertamente, esta manera de plantear el problema resuena en un buen número de los argumentos que problematizan la idea de correspondencia hasta nuestros días. ${ }^{4}$ En palabras de Nietzsche:
Entre dos esferas absolutamente distintas, como lo son el sujeto y el objeto, no hay ninguna causalidad, ninguna exactitud, ninguna exposición, sino a lo sumo, una conducta estética, quiero decir: un extrapolar alusivo, un traducir balbuciente a un lenguaje completamente extraño, para lo que, en todo caso, se necesita una esfera intermedia y una fuerza mediadora, libres ambas para poetizar e inventar (1990, p.30).

Ciertamente, los presupuestos de este argumento hacen ver no sólo la correspondencia, sino en general la referencia lingüística, como un misterio irresoluble. El más determinante de estos presupuestos, a mi modo de ver, es la exacerbación de la dicotomía entre sujeto y objeto y la imagen representacionalista del conocimiento propios de la filosofía moderna. En efecto, en lugar de superar esta dicotomía, la critica al idealismo y el nominalismo radical de Nietzsche en este texto consiguen llevarla hasta sus últimas consecuencias. De una lado, encontramos al ser humano, que es pensado aquí como enteramente desligado del mundo, pero ubicado ante él en una relación que pretende (como medio de sobrevivencia) ser intelectual (impulsoimagen-palabra). Del otro, está el mundo, que se escapa por naturaleza al conocimiento como representación adecuada, porque, como afirma el célebre parágrafo 109 de La Gaya Ciencia, "el carácter general del mundo es, para toda la eternidad, 
caos, no en el sentido de que falte la necesidad, sino en el de que falta el orden, la articulación, la forma, la belleza y como quieran llamarse todas nuestras categorías humanas". (2014, p.794)

Como consecuencia, el ser humano debe siempre inventar e imponer sus categorías sobre el caótico devenir de lo real, olvidando que lo hace, fingiendo, "mintiendo inconscientemente". (Nietzsche 1990, p.25) El ser humano no es aquí parte y participante de la realidad, sino una suerte de extranjero ante un mundo extraño y siempre inaccesible, caracterizado por el flujo sin medida y la ininteligibilidad, en el cual tiene que imponer, como expresión de su voluntad, orden y estructura para servir sus propios propósitos y necesidades. En uno de los Fragmentos Póstumos (9 [35] 927)) que sirve de base a La Voluntad de Poder, la afirmación según la cual no hay verdad es presentada como la presuposición del nihilismo, cuya forma más extrema "coloca el valor de las cosas precisamente en que a ese valor no le corresponde ni le correspondió nunca ninguna realidad, sino que es sólo un síntoma de fuerza por parte de quien instituye el valor" (2015, p.242).

El sueño moderno de control y dominio sobre el mundo, basado en el ideal de un sujeto autónomo se consuma aquí trágicamente (ipues incluso el sujeto es producto de la voluntad, una ficción más!). ¿Qué mayor dominio sobre el mundo puede ser pensando que la supresión del mundo, es decir, la desconexión radical con respecto a una realidad cuya alteridad puede interpelarnos, exigirnos, confrontarnos y reclamarnos, haciendo tambalear nuestras interpretaciones y proyectos, mediante la afirmación de que toda realidad (interna o externa) es por completo nuestra hechura y tiene la forma que le damos a voluntad?

Dejemos de lado las inevitables inconsistencias y paradojas a las cuales conduce esta posición (ila ontología del caos, la visión evolucionista del conocimiento y la antropología de la desconexión son las afirmaciones sobre lo real en las que se basa el argumento según el cual no es posible hacer ninguna afirmación sobre lo real!). ${ }^{5} \mathrm{Me}$ interesa más señalar que la radicalidad y originalidad del argumento no está en que los conceptos y categorías son invenciones nuestras, producto de la capacidad creadora de los seres humanos, sino más bien en la visión desilusionada del ser humano y su capacidad creadora. En efecto, por lo menos desde Nicolás de Cusa (1401-1464) hace parte del repertorio intelectual occidental la idea según la cual las matemáticas (y en general los conceptos) son creaciones libres de la mente humana, no sólo independientes de las impresiones sensibles, sino también diferentes de una reproducción reflexiva basada en relaciones ideales. Pero, en el caso de de Cusa, dado que la mente misma es creada por Dios, lleva en sí la imago Dei y por tanto tiene una dignidad y capacidad tales que sus creaciones libres dan conocimiento del modo como es el mundo, también creado por Dios y portador en grado menor de su imagen (Cf. Pannenberg 1971, p.15ss). De este modo se garantizó tradicionalmente la copertenencia del ser humano y el mundo, tanto como la posibilidad de la correspondencia 
propia del conocimiento, hasta bien entrado el siglo XVIII (Cf. Brooke 1991, p.19). Sin Dios en el horizonte, entre el intelecto y el mundo prima la arbitrariedad y toda creación es mera invención (Erfindung).

\begin{abstract}
iHemos abandonado la tierra y hemos subido a la nave! iHemos dejado todo los puentes detrás nuestro [...]!

¿Hacia dónde nos movemos nosotros? ¿Lejos de todos los soles? ¿No nos precipitamos permanentemente? ¿Y también hacia atrás, hacia delante, hacia todos los lados? ¿Hay aún un arriba y un abajo? ¿No erramos como a través de una nada infinita? (Nietzsche 2014, parágrafos 124 y 125).
\end{abstract}

En este sentido, algunos de los seguidores de Nietzsche han señalado que la imposibilidad de la verdad es una consecuencia directa de la "muerte de Dios" y que un pensamiento realmente "secularizado" debería desprenderse para siempre de esta noción (y de otras semejantes, como las de bondad y justicia), la cual es un rezago de épocas pasadas. ${ }^{6}$ Pero, ¿no es sólo un tipo de correspondencia, la isomórfica, y una sola concepción de conocimiento, la representacionalista, lo que ha sido problematizado? ¿Es posible reconstruir el realismo sin basarlo en la función garantizadora de la correspondencia ejercida por Dios? A mi modo de ver, sin quererlo, Nietzsche mismo demuestra con sus metáforas lo que niega con su teoría de la metáfora.

(3) Los conceptos, en tanto que metáforas, son para Nietzsche formas de conectar ("extrapolar", "traducir") "alusivamente", "estéticamente", las diferentes esferas (mundo, impulsos nerviosos, imágenes, palabras) cuya radical heterogeneidad hace imposible la correspondencia. Como vimos, los conceptos no expresan la esencia de las cosas, sino que proyectan arbitrariamente categorías humanas sobre el caos de lo real. En este sentido, si bien el concepto "se limita a designar las relaciones de las cosas con respecto a los hombres" (Nietzsche 1990, p.22, p.28) y no las cosas mismas, lo hace siempre falseado la experiencia primordial, si es que se puede hablar de este modo, pues el flujo incesante, caracterizado por la diversidad de cada momento, es reducido a unidad (Nietzsche 1990, p.24). Por eso, un sistema conceptual es una construcción humana que semeja un "gran columbiarium"; se trata de "la necrópolis de las intuiciones" (Nietzsche 1990, p.33).

El arte y el mito, a diferencia de la ciencia, aceptan esta realidad y deciden "fingir conscientemente" (Nietzsche 1990, p.37), es decir, permitir que el intelecto arroje metáforas sin orden alguno, jugando "libremente" con el andamiaje conceptual, confundiéndolo, mezclándolo, destruyéndolo y volviéndolo a juntar (Nietzsche 1990, p.34). En todo caso, la metáfora es para Nietzsche una conexión arbitraria entre esferas "realmente" incomunicables. Fingimos una conexión donde no la hay. Para expresar esto, Nietzsche se vale de un conjunto extraordinario de metáforas, símiles y analogías. Su precisión y economía poéticas, su establecimiento de relaciones entre ámbitos dispares de la realidad para sugerir lo que no puede ser mejor dicho de otro 
modo, en una palabra, su poder de comunicar indirectamente lo que la descripción literal es incapaz de mostrar, dan razón a Antonio Machado cuando decía que los poetas tienen que aprender a hacer metáforas de los filósofos, mientras que estos deben aprender del escepticismo de los poetas. Entre las metáforas y símiles de Nietzsche sobre la desconexión, en "Sobre verdad y mentira" cabe destacar las siguientes:

Se podría pensar en un hombre que fuese completamente sordo y jamás hubiera tenido ninguna sensación sonora ni musical; del mismo modo que un hombre de estas características se queda atónito ante las figuras acústicas de Chladni en la arena, descubre su causa en las vibraciones de la cuerda y jurará entonces que, en adelante, no puede ignorar lo que los hombres llaman «sonido», así nos sucede a todos nosotros con el lenguaje. (23)

Cabe admirar en este caso al hombre como poderoso genio constructor, que acierta a levantar sobre cimientos inestables y, por así decirlo, sobre agua en movimiento, una catedral de conceptos infinitamente compleja: ciertamente, para encontrar apoyo en tales cimientos debe tratarse de un edificio hecho de telarañas, suficientemente liviano para ser transportado por las olas, suficientemente firme para no desintegrarse ante cualquier soplo de viento. (27)

Además de estas constelaciones de relaciones analógicas, son remarcables la imagen del conocimiento como el "juego de dados de los conceptos [en el que] se denomina «verdad» al uso de cada uno según su designación” (27); la comparación entre el científico y "el astrólogo [que] considera las estrellas al servicio de los hombres y en conexión con su felicidad y con su desgracia" (28) ; o la referencia a "un pintor que careciese de manos y quisiera expresar por medio del canto el cuadro que ha concebido". (30) ¿Qué hace que estas analogías y metáforas consigan expresar con tanta contundencia la tesis Nietzscheana de la desconexión entre el mundo, el lenguaje y el intelecto?

Esta pregunta apunta a la naturaleza, estructura y función de la metáfora, las cuales son utilizadas por Nietzsche a la vez que negadas. A diferencia del lenguaje literal, los usos analógicos del lenguaje se basan en el establecimiento de relaciones, de modo que al comparar o asimilar un elemento o aspecto de la realidad con otro que pertenece a un orden enteramente diferente, se descubren entre ellos parecidos que revelan, como el concepto no consigue hacerlo, su modo de ser. Los sistemas conceptuales son (como) catedrales hechas de telaraña para resistir el movimiento del agua del mundo sobre el que se asientan. Sólo porque los conceptos, las catedrales, las telarañas y el agua tienen un modo de ser que nos es familiar y conocido puede la comparación ser hecha. Del mismo modo, la metáfora no funciona, no dice nada o resulta forzada y artificiosa, si trata de conectar aspectos o elementos de la realidad cuyo vínculo no se basa en un parecido "natural". Una metáfora fallida no consigue descubrir nada de lo real. En palabras de Ian Barbour:

Principia 21(1): 77-98 (2017). 


\begin{abstract}
en una metáfora se produce una configuración nueva mediante la yuxtaposición de dos marcos de referencia de los cuales el lector debe ser simultáneamente consciente (...) Sin embargo, no se trata de una ficción útil, un simple fingimiento, un juego de hacer-creer sin relación con la realidad. La metáfora afirma que hay analogías significantes entre las cosas comparadas. (Barbour 1974, p.13)
\end{abstract}

Interesantemente, esta capacidad de hacer ver relaciones entre ámbitos diferentes de la realidad, que se basa en un conocimiento previo y tácito del modo de ser de las cosas, además de hacer posibles y efectivas las metáforas de Nietzsche, es tematizada por los experimentos acústicos conducidos por Ernst Chladni (1756-1827), a los que se refiere la primera metáfora que citamos arriba. Este físico alemán, considerado el padre de la acústica, diseñó un experimento en el que conectaba una fina placa de metal, cubierta de arena, a diferentes fuentes de sonido que la hacían vibrar. El resultado sorprendente es que la figura que se forma en la área corresponde a la frecuencia del sonido. iDe este modo se pueden visualizar las ondas sonoras! ${ }^{7}$ La continuidad entre esferas de lo real, cada una de las cuales es (ipor supuesto!) cualitativamente diferente de las demás, y no su fragmentación y desconexión es el descubrimiento por excelencia de la metáfora y su condición de posibilidad.

\title{
3. El realismo como condición de inteligibilidad
}

Del mismo modo que el poder expresivo de las metáforas se basa en su capacidad de establecer relaciones entre ámbitos de lo real cuyo modo de ser (al menos parcialmente y siempre desde una perspectiva) es expresado en ellas y debe ser "conocido" por el intérprete, la comunicación en general no funciona sin la presuposición de la referencia a la realidad. Está tesis ha sido defendida por John Searle con su famoso "Argumento trascendental a favor del realismo externo" (1995, p.177ss). Para él, un argumento trascendental es el que asume que cierta condición, estado de cosas o práctica se da efectivamente y luego trata de mostrar las presuposiciones de tal condición o práctica (1995, p.183). En este caso, el punto de partida es la comunicación cotidiana, es decir, el conjunto de prácticas mediante las cuales tratamos de comunicarnos con los otros mediante un lenguaje público sobre un mundo común. Desde el punto de vista de los hablantes, una condición de inteligibilidad del uso normal de un gran número de actos de habla es la presuposición de que con el lenguaje nos referimos a una realidad que tiene un modo de ser independiente de nuestras representaciones. Sin esta presuposición, no funcionaría la comunicación. Y tenemos la experiencia de que funciona. ${ }^{8}$

Ciertamente, este argumento no pretende ser una prueba de la realidad del mundo exterior. Pues, a diferencia del famoso argumento de Moore (1983), la afirmación

Principia 21(1): 77-98 (2017). 
del realismo externo no puede ser pensada como una proposición que describe un estado de cosas, es decir, no está implicada en otras proposiciones ni se sigue de ninguna otra afirmación (e.g. "Tengo dos manos"). Se trata más bien de la condición de posibilidad de cualquier afirmación con sentido sobre el mundo (Searle 1995, p.181). Esto es lo que significa que el realismo es una condición de inteligibilidad de un gran número de usos del lenguaje. Adicionalmente, la presuposición del realismo no es una teoría sobre la realidad. Es decir, todo lo que el argumento indica es que no podemos comunicarnos si no asumimos, como una condición pragmática del uso del lenguaje, que este se refiere a una "realidad públicamente accesible, a una realidad que es ontológicamente objetiva" (Searle 1995, p.186); pero no implica compromiso alguno con una teoría sobre cómo es el mundo, de qué está hecho, qué cuenta como últimamente real y asuntos semejantes. Consecuentemente, la presuposición del realismo tampoco implica alguna tesis epistemológica, esto es, no dice nada sobre hasta qué punto y de qué modo puede ser conocida la realidad. En palabras de Searle, "el realismo es la posición según la cual existe un modo como son las cosas lógicamente independiente de todas las representaciones humanas. El realismo no dice nada acerca de cómo son las cosas, sino sólo que hay un modo como son" (Searle 1995, p.155).

El alcance y sentido de este argumento puede explorarse mediante un sencillo experimento mental. Imaginemos un tipo de práctica comunicativa en la que los hablantes no presupusieran que con su lenguaje se refieren a una realidad independiente del lenguaje y las prácticas cognitivas. Si bien es posible imaginar algo así, el tipo de sonidos que emitirían difícilmente podría considerarse un lenguaje y, más aún, su interacción no podría considerarse propiamente comunicativa. O más bien, aún si algo podría ser "expresado", todas las otras funciones y usos del lenguaje se perderían. Esto es verdad incluso para la poesía, como muestra el experimento de Vicente Huidobro en Altazor (1931), en donde la búsqueda del movimiento "creacionista", una de las cumbres de las vanguardias latinoamericanas de principio de siglo XX, alcanza a la vez su plenitud y culminación. El creacionismo es una "teoría estética" para la cual el poeta debe intentar producir poemas en los cuales "cada parte constitutiva, y todo el conjunto, muestra un hecho nuevo, independiente del mundo externo, desligado de cualquier otra realidad que no sea la propia, pues toma su puesto en el mundo como un fenómeno singular, aparte y distinto de los demás fenómenos" (Huidobro, "El Creacionismo"). En ese sentido, el lenguaje poético debe dejar de "representar" el mundo para generar su propio mundo. ${ }^{9}$ Cuando la intención creacionista se radicaliza, el lenguaje poético deja de referir en absoluto. El poema del "viaje en paracaídas", que es el poema de la pérdida del lenguaje y la caída en el silencio en siete cantos, comienza: "Nací a los treinta y tres años, el día de la muerte de Cristo; nací en el Equinoccio, bajo las hortensias y los aeroplanos del calor". Y termina:

Principia 21(1): 77-98 (2017). 
Montañendo oraranía
Arorasía ululacente
Semperiva
$\quad$ Ivarisa tarirá
Campanudio lalalí
Auriciendo auronida
Lalalí

Iiio

Ai a i ai a iiii o ia

El final del experimento es o bien el silencio y la renuncia a la poesía misma, o el regreso y la confirmación de la referencia como condición sin la cual no es posible crear imágenes poéticas. Esto no significa que el poema "copie" el mundo, sino que la creación de una imagen poética, con la cual se establece o se descubre una relación inusitada entre aspectos de la realidad, la cual no es ella misma un objeto más entre los objetos del mundo, requiere que el leguaje poético nombre tales aspectos presuponiendo que existen con independencia del poema. La gradual pérdida de la referencia, si bien libera al lenguaje para jugar "el simple sport de los vocablos/ de la pura palabra y nada más" (Canto III, verso 144), hasta hacerlo sólo ritmo y melodía, reduce hasta el límite mínimo su capacidad de decir algo, como quien olvida la letra de una canción y no puede ya sino tararearla. Por eso, "Después nada nada / rumor aliento de frase sin palabra" (Canto III, 159).

Pero, se podría contra-argumentar que el hecho de que el leguaje se refiera a un mundo compartido no significa que este tenga una realidad independiente del lenguaje, los esquemas conceptuales y las prácticas discursivas de los interlocutores. En efecto, una "realidad públicamente accesible" no es lo mismo que "una realidad que es ontológicamente objetiva", como parece suponer el argumento de Searle. A mi modo de ver, su versión del argumento trascendental a favor del realismo externo sólo consigue mostrar que la presuposición de una realidad pública es una condición de posibilidad de la comunicación, pero no que esta realidad es "independiente de la representación". En efecto, como mencionamos arriba, el "axioma hermenéutico" se basa en el reconocimiento de que el mundo compartido es siempre previamente articulado y constituido lingüística y conceptualmente, es decir, de que es ya interpretado, y sólo por eso es un mundo con sentido y puede ser compartido por aquellos que hablan el mismo lenguaje.

Puesto de otra manera: el reto al que debe responder un argumento a favor del realismo no concluye con una defensa de la referencia lingüística, sino con la defensa de que aquello a lo que nos referimos tiene un modo de ser independiente de nuestras prácticas discursivas y formas de actuar en el mundo que además debe poder ser 
captado, al menos parcialmente y desde cierta perspectiva, por ellas. Pues, todavía es posible afirmar que "un signo que es utilizado de un modo particular por una comunidad particular de hablantes puede corresponder a objetos particulares dentro del esquema conceptual de esos usuarios. [Pero] Los objetos no existen independientemente de esquemas conceptuales". (Putnam 1981, p.52). El problema no es siquiera que las palabras correspondan con los objetos de modo adecuado, sino que la correspondencia sólo es posible al interior de un esquema conceptual que establece la relación de referencia y determina lo que cuenta como cada objeto particular. Por eso, aún en posturas "internalistas" es posible mantener la correspondencia como uno de los elementos del concepto de verdad. En palabras de Putnam:

La verdad es un tipo de aceptabilidad racional (idealizada) - alguna clase de coherencia entre nuestras creencias entre ellas mismas y con nuestras experiencias tal y como esas experiencias son representadas en nuestro sistema de creencias - y no la correspondencia con un 'estado de cosas' independiente de la mente o el discurso (Putnam 1981, p.50).

Así, el criterio de verdad, incluso definido en términos coherentistas, puede seguir incluyendo la idea de un tipo de adecuación o ajuste con la experiencia (las cursivas en el texto son de Putnam); pero los contenidos de la experiencia, los objetos y relaciones que constituyen el mundo que experimentamos, son constituidos por un esquema conceptual. En este sentido al menos, (que obviamente descarta el isomorfismo) la verdad por correspondencia no es incompatible con la relatividad conceptual.

Lo que está en juego, pues, es el significado de la relatividad conceptual, es decir, el modo como debe entenderse que los contenidos de la experiencia o "los objetos del mundo" dependan de nuestros esquemas conceptuales y prácticas discursivas. ¿Cómo debe comprenderse esta dependencia? Si bien Searle afirma una y otra vez que el realismo es compatible con la relatividad conceptual, no está dispuesto a renunciar a la distinción entre nuestras descripciones y aquello que describen. Acepta que dado que el lenguaje tiene carácter "convencional", no hay una única descripción verdadera sobre el mundo, pues toda denominación y descripción es relativa a un conjunto de categorías lingüísticas y no está inscrita en las cosas mismas. Pero nos previene enfáticamente de concluir apresuradamente de aquí que aquello que es descrito "sólo puede existir relativamente a un grupo de categorías" (1995, p.166).

Estoy totalmente de acuerdo en que esta conclusión no se sigue. Sin embargo, no me parece del todo claro que la presuposición de una realidad pública a la cual se refiere nuestro lenguaje, una vez aceptado el carácter convencional del lenguaje, implique la presuposición de que esta realidad es totalmente independiente de nuestros esquemas conceptuales y prácticas discursivas (o independiente en el sentido en que es relevante para el realismo). Como un presupuesto absolutamente general y enteramente formal, la existencia de una realidad independiente es sin duda una 
condición necesaria de la comunicación. En particular cuando hacemos descripciones sobre el modo como es el mundo, es decir, cuando realizamos actos de habla con pretensiones de verdad, asumimos que "hay un modo como es el mundo". De lo contario, tales actos de habla fallarían al presentar una pretensión de verdad en el "uso normal" del lenguaje asertivo y simplemente no podríamos comprenderlos (Searle 1995, pp.186ss; cf. Habermas 2002, pp.44ss). La contradicción auto-performativa que es generada por frases como "El monte Everest tiene nieve en la cima, pero no existe una realidad externa (o, pero esta frase no se refiere a nada)", da buena cuenta de esto.

Pero, esta presuposición enteramente general y formal de gran parte de los usos del lenguaje deja algo irresuelto en cada enunciación particular. Pues, si bien en cada acto de habla particular en el que nos referimos a una realidad públicamente accesible, esta no puede ser enteramente un producto de nuestras prácticas enunciativas, la referencia misma presenta al objeto desde una perspectiva mediante los recursos lingüísticos de un lenguaje y un esquema conceptual particulares. No es suficiente con presuponer que hay una realidad independiente de la representación, a la que creemos o pretendemos referirnos al hablar. Es necesario mostrar que lo que decimos depende, en algún sentido, del modo de ser de lo real; y que, en el caso de enunciados descriptivos, el modo de ser de aquello de lo que hablamos es relevante para determinar el éxito de tales enunciados, es decir, su verdad.

Por esto, el argumento trascendental a favor del realismo requiere ser complementado con una aclaración que reconcilié el carácter "ontológicamente objetivo" de la realidad y el hecho de que esta siempre es interpretada. ¿Es posible lograr algo semejante?

\section{Hacia un realismo pluralista}

\section{1. ¿Qué significa la independencia de la realidad?}

Como hemos visto, de una respuesta apropiada a esta pregunta depende una concepción del realismo capaz de incorporar la historicidad del conocimiento. En primer lugar, es claro que la independencia de la realidad que requiere el realismo no implica que esta pueda ser conocida con independencia de toda perspectiva, es decir, de modo desligado a los valores, intereses, necesidades y sistemas conceptuales de quien conoce. El carácter relacional del lenguaje y de todos nuestros actos cognitivos impiden lo que se ha solido denominar "el punto de vista de Dios", es decir, la captación o representación de la realidad independientemente de cualquier punto de vista o esquema representacional. ${ }^{10}$ Pero esto sugiere ya que lo real tampoco es simplemente el producto de nuestras prácticas cognitivas, sino que estas lo presuponen como aquello sobre lo cual pueden ser puntos de vista. 
Es necesario distinguir entonces varios tipos de dependencia de lo real con respecto a la mente, nuestras prácticas, nuestro lenguaje o nuestros esquemas conceptuales. En la literaria actual se suele distinguir entre tres tipos de dependencia (cf. Kukla 2000, pp.19ss; Boghossian 2006, pp.12ss; Searle 1995; Moore 1983). En primer lugar, tenemos la dependencia causal propia de las cosas y artefactos elaborados por los seres humanos. En el sentido más básico y plano, la existencia de máquinas, instrumentos, edificios y otras obras semejantes depende sin duda de la acción y las prácticas creativas de los seres humanos, pero una vez producidos continúan existiendo así no haya nadie más que los piense, los use o los nombre. Un segundo tipo de dependencia es de tipo psicológico: la existencia de ciertos estados y entidades cesa si dejan de ser percibidos por alguien, como en el caso del dolor o una emoción. Finalmente, el tipo más fuerte de dependencia es la constitutiva: en estos casos, los objetos o hechos son constituidos por la conciencia, el lenguaje, los esquemas conceptuales o las prácticas discursivas, de modo que no tienen un tipo de existencia por fuera de la actividad de la conciencia, las prácticas discursivas o los juegos lingüísticos que los han dado a luz.

Ciertamente, un amplio ámbito de la realidad humana tiene un tipo de realidad que se caracteriza por este tercer tipo de dependencia. Las normas e instituciones sociales son un ejemplo de ello. En el momento en que dejen de ser "reconocidas" desaparecen, o son transformadas tan pronto como cambian los sistemas de normas e interpretaciones que las constituyen. No podemos explorar aquí con detalle lo que significa este tipo de dependencia, a la cual se han dedicado un buen número de trabajos de ontología social en los últimos años (Searle 1995; Smith 2010; Elder-Vass 2013). Baste con señalar que estos tres tipos de dependencia pueden ser compatibles con el realismo, ${ }^{11}$ en el sentido en que aquello que tiene un tipo de realidad dependiente en cualquiera de los tres sentidos, puede a la vez ser considerado independiente desde el punto de vista del intérprete que trata de comprenderlo y estudiarlo. En otras palabras, la posibilidad de estudiar “objetos" constituidos por el discurso, el lenguaje, las prácticas conceptuales, así como de dar cuenta de los procesos mediante los cuales estos fueron constituidos, implica que la distinción entre lo real y las interpretaciones de lo real no puede nunca ser borrada del todo. (El regreso al infinito y la inconsistencia auto-referencial serían el precio vergonzoso de quien afirme que los objetos socialmente construidos que estudia mediante conceptos socialmente construidos no son nada más que construcciones sociales llevadas a cabo por sus propios conceptos. Irónicamente, el lenguaje y la teoría siguen aquí pensándose como un espejo, no ya del mundo sino del intérprete -y cuando este se disuelve en el discurso mismo, como un espejo del espejo.)

Evidentemente, este tipo de independencia, que es compatible con las tres formas de dependencia, no es la del objetivismo. Pues, si bien ser interpretado no es lo mismo que ser construido por el intérprete (aun si lo interpretado ha sido construido 
por otros), la distinción necesaria entre lo interpretado y la interpretación no es la distancia entre sujeto y objeto de la epistemología tradicional. Aquí encontramos un cuarto tipo de dependencia, que podemos denominar hermenéutica, en la cual reside la clave para conciliar realismo e historicidad.

\subsection{La interpretación sólo es posible como forma de contacto con lo real}

Buena parte de la discusión actual entre realismo y anti-realismo parece basarse en una u otra versión del presupuesto Nietzscheano de la desconexión de esferas al que nos referimos antes, así como en el modelo representacionalista del conocimiento (cf. Habermas 2002, pp.40ss; Dreyfus y Taylor 2015, p.2, p.92). En un extremo, la totalidad de lo real es producto de la construcción interpretativa de los seres humanos; en el otro, lo real tiene un modo de ser absolutamente independiente que debería poder ser captado y descrito tal cual es en sí mismo, sin interferencia de los puntos de vista, intereses, valores y formas de conocimiento humanos. En ambos casos se pierde el carácter relacional del conocimiento y la interpretación, pues "la realidad" es concebida siempre como el otro polo de la actividad humana (ya como su producto o como aquello que debe ser "objetivamente" descrito y controlado). Pero más que representar o copiar directamente la realidad, nuestras actividades interpretativas y sus productos son ya parte de la realidad en la cual participamos (Cf. Smith 2010, p.170; Elder-Vass 2012, p.247). Por eso, un realismo que pueda integrar el pluralismo epistemológico requiere de una comprensión adecuada de lo que significa nuestro trato interpretativo con el mundo.

Esta forma de trato interpretativo implica una permanente relación de interacción y co-dependencia entre nuestros leguajes, esquemas conceptuales y prácticas discursivas y el mundo, el cual, si bien no es "inventando" por nuestras interpretaciones, sólo nos es accesible en ellas. De este modo, nuestros sistemas interpretativos y prácticas cognitivas son un modo de contacto con lo real, y no un muro que nos separa de ello y nos encierra auto-referencialmente. En nuestros tratos con el mundo, creativos e interesados como todas nuestras actividades,

queda descubierta y accesible a cada cual la naturaleza del mundo circundante. En los caminos, carreteras, puentes y edificios la ocupación descubre la naturaleza en determinada dirección. Un andén techado tiene en cuanta el mal tiempo; las instalaciones del alumbrado público, la oscuridad, es decir, la particular mudanza de la presencia y ausencia de la claridad del día. (Heidegger 2009, §15, p.93)

De este modo, que la realidad sea siempre interpretada y articulada en nuestras prácticas no significa que nuestras interpretaciones proyecten arbitrariamente un orden

Principia 21(1): 77-98 (2017). 
sobre el caos primordial, como creía el joven Nietzsche, sino que esta tiene un carácter relacional que hace posible nuestras interpretaciones (las cuales son ellas mismas parte de lo real). Para aclarar esta tesis central es necesario tanto una comprensión adecuada de lo que significa la historicidad de nuestras formas de conocer, como un concepto de realidad en el que nuestra interpretación quede incluida.

¿Cómo podemos comprender el carácter situado de la racionalidad y el conocimiento? Los conceptos de "agencia enganchada" y "horizonte de pre-comprensión", desarrollados en la filosofía hermenéutica, son aquí centrales. La dicotomía entre sujeto y objeto, propia de la imagen representacionalista del conocimiento interpreta al sujeto como un "agente desenganchado". Este es un agente cuyo modo primordial de relación con la realidad es cognitiva, esto es, mediada por una serie de operaciones y procedimientos que le permiten elaborar una imagen del mundo mediante el procesamiento de "bits" de información tomados del medio ambiente, los cuales se dejan atrapar independientemente de los valores, intereses y propósitos prácticos del agente, tanto como de todo punto de vista parroquial perteneciente a su tradición, cultura y forma de vida. (Taylor 1993, p.320) Como hemos visto, un tipo de agente semejante es también presupuesto cuando, en oposición a lo anterior, se afirma que la realidad es enteramente construida por el agente. En ambos casos, se trata de un agente sin mundo, o mejor, de un agente que no es él mismo parte de la realidad.

Esta imagen es sin duda inapropiada pues no capta el tipo de seres que somos. Nuestra experiencia del mundo, nuestro lenguaje, nuestras prácticas y nuestros esquemas conceptuales sólo funcionan y tienen sentido para el tipo de agentes que somos, es decir, seres corpóreos enganchados en el trato práctico con el mundo, el cual constituye la forma primordial de nuestra comprensión. Este carácter pre-reflexivo y práctico de nuestra comprensión originaria del mundo es uno de los grandes aportes Ser y Tiempo de Heidegger. Antes de toda tematización, de toda reflexión e investigación racional estamos ya ocupados (besorgen) en diferentes modos de tratar con el mundo, el cual tiene ya siempre un sentido que descubrimos, justamente, en la ocupación (cf. 2009, §12-16). Por eso, el hecho de que el mundo sea siempre interpretado no significa que proyectamos sobre él arbitrariamente nuestras interpretaciones, pues nuestra relación primordial con el mundo no es la de un agente desvinculado de un mundo al que trata de dar sentido. Por el contrario, estar en el mundo es participar activamente en alguna actividad mediante la cual tratamos habilidosamente con él (Dreyfus y Taylor 2015, pp.93-101).

Como todo artesano sabe, la maestría en la práctica depende tanto del conocimiento del modo de ser de los materiales, como de su utilización creativa para ciertos propósitos y necesidades. Lejos de ser una materia bruta no interpretada, carente de todo carácter y determinación, maleable al extremo de la irrelevancia, la realidad tiene un modo de ser que se impone y exige ser reconocido en nuestros tratos habilidosos con el mundo. Nuestras prácticas interpretativas y constructivas sólo funcionan 
si consiguen captar la realidad desde cierto punto de vista, es decir, mediante ciertos instrumentos conceptuales y materiales y con vistas a satisfacer ciertos intereses y necesidades. Así, "en el sentido más básico y preconceptual la comprensión que tenemos del mundo no es solamente construida o determinada por nosotros. Más bien, se trata de una "coproducción" de nosotros y el mundo". (Dreyfus y Taylor 2015, p.93)

Esta forma de comprensión propia de la ocupación y el envolvimiento práctico en el mundo constituye el horizonte de sentido de toda investigación racional y se articula en la cultura, la tradición y las formas de vida, las cuales lejos de representar un obstáculo para el conocimiento, lo hacen posible. Toda actividad racional es histórica, en este sentido, en tanto que parte de aquello que ya ha sido comprendido y es anterior a toda tematización. Gadamer reelabora esta importante tesis fenomenológica identificando este elemento previo de sentido con los "prejuicios" que nos son dados por nuestra pertenencia a una tradición. Con esto, da un significado más claro a la estructura de la pre-comprensión propuesta por Heidegger, la cual se basa en tres elementos: un haber previo (vorhaben), un punto de vista previo (vorsicht) y un concepto previo (vorgriff) $(2009$, §32, p.169). Ahora bien, los prejuicios que constituyen la pre-comprensión no son creencias necesariamente falsas y distorsionadas, aceptadas solo por autoridad, las cuales podrían limitar la investigación racional. Por el contrario, los prejuicios representan la manera en la cual la tradición ha interpretado el mundo, o mejor, la manera como el mundo se muestra en la tradición desde alguna de sus perspectivas. Aceptarlos y mantenerlos no es un acto de obediencia ciega, sino que implica el reconocimiento y la afirmación racionales (Gadamer 2007, p.282). El punto clave aquí es que los prejuicios pueden ser verdaderos o falsos con respecto a la cosa que es interpretada en ellos (Gadamer 2007, p.281, p.270). Por eso, en palabras de Heidegger "la posibilidad del conocimiento más originario" que es propia de la interpretación

sólo será asumida de manera auténtica cuando la interpretación haya comprendido que su primera, constante y última tarea consiste en no dejar que el haber previo, la manera previa de ver y la manera de entender previa le sean dados por simples ocurrencias y opiniones populares, sino en asegurarse del carácter científico del tema mediante la elaboración de esa estructura de prioridad a partir de las cosas mismas. (2009, §32, p.172, mí énfasis)

Como consecuencia, la interpretación es una actividad abierta que parte de lo dado en la tradición, pero no termina allí. El horizonte de pre-comprensión es continuamente transformado y ensanchado mediante nuevas interpretaciones, las cuales son movilizadas no sólo por los intereses, valores y necesidades del intérprete o como resultado de contingencias históricas, sino por la alteridad de la realidad, que no se deja nunca reducir ni captar del todo desde un solo punto de vista. El carácter histórico de la racionalidad y el conocimiento significa no sólo que estos están siempre 
situados, sino también que están abiertos a una permanente transformación de cara a lo real, cuyo modo de ser se resiste a ciertas interpretaciones e impone exigencias ineludibles para que nuestras prácticas cognitivas seas exitosas. La incapacidad de escuchar lo real y responder a sus exigencias constituye, de este modo, el contenido de la noción de falsedad, que no desaparece al reconocer la historicidad de la verdad.

\section{Conclusión}

En tanto que nuestra comprensión del mundo es moldeada por los valores, las creencias y las interpretaciones de la cultura a la que pertenecemos, tanto como por nuestros intereses y modos de conocer, no hay para nosotros un conocimiento del mundo libre de presupuestos. Pero, al mismo tiempo, dado que antes que una representación del mundo, la forma primordial de la comprensión consiste en modos de actuar y estar ocupados en el mundo, nuestras prácticas e interpretaciones no podrían tener la forma que tienen ni constituir una manera hábil de tratar con el mundo a menos que éste se manifieste en ellas tal y como es, dejándose captar al menos en ciertos de sus aspectos y modos de ser. He denominado dependencia hermenéutica a este tipo de co-dependencia entre nuestras prácticas cognitivas, nuestro lenguaje y esquemas conceptuales y el mundo.

Afirmar que no puede haber un conocimiento absoluto del mundo, porque todo conocimiento presupone un horizonte de pre-comprensión local, no significa que cada interpretación sea una invención arbitraria de la realidad. Nuestros esquemas conceptuales, prácticas discursivas y lenguajes sólo pueden contribuir en la construcción de la realidad en la medida en que sean ya de suyo una manera hábil de captar y utilizar para ciertos propósitos algunos aspectos y modos de ser de los objetos con los que tratan. Así, el lenguaje, las prácticas discursivas y los esquemas conceptuales no deben ser comprendidos como barreras que bloquean nuestro acceso al mundo, sino más bien como el punto de interacción y contacto mediante el cual participamos en la realidad. Esto hace posible restablecer el realismo como una posición que acepta e incorpora la historicidad y la pluralidad de nuestros modos de conocer, pues el éxito o el fracaso de nuestras prácticas depende de su capacidad para captar y utilizar, para nuestros propósitos y necesidades, la realidad tal como ella es en sí misma, si bien se nos da siempre desde la perspectiva que permiten nuestras prácticas. Tal éxito y fracaso es siempre un indicador de la verdad o falsedad de lo que decimos y creemos sobre la realidad, cuya alteridad no se deja reducir ni domesticar por nuestras interpretaciones - que son también parte suya.

Principia 21(1): 77-98 (2017). 


\section{Referencias}

Barbour, I. 1974. Myths, Models and Paradigms. A comparative Study in Science and Religion. New York: Harper and Row.

Boghossian, P. 2006. Fear of Knowledge. Against relativism and constructivism. Oxford: Oxford University Press.

Borges, J. L. 1997. El Aleph. Madrid: Alianza.

Brooke, J. H. 1991. Science and Religion. Some historical perspectives. Cambridge: Cambridge University Press.

Dilthey, W. 1974. Teoría de las Concepciones del mundo. Madrid: Revista de Occidente.

- 1978. La conciencia histórica y la concepción del mundo. In: Teoría de la concepción del mundo. México: F.C.E.

Dreyfus, H.; Taylor C. 2015. Retrieving realism. Cambridge Ma: Harvard University Press.

Clark, M. 1990. Nietzsche on Truth and Philosophy. New York: Cambridge University Press.

Elder-Vass, D. 2013. The Reality of Social Construction. Cambridge: Cambridge University Press.

Foucault, M. 2011. La verdad y las formas jurídicas. Barcelona: Gedisa.

Gadamer, H. G. 1975[2007]. Verdad y Método I. Salamanca: Sígueme.

Goodman, N. 1978. Ways of Worldmaking. Indianapolis: Hackett.

Habermas, J. 2002. Verdad y Justificación. Madrid: Trotta.

Heidegger, M. 2009. Ser y Tiempo. Trad. Jorge Rivera. Madrid: Trotta.

Huidobro, V. 1931[1992]. Altazor. Temblor de Cielo. Bogotá: REI, Cátedra.

—. El creacionismo. http://www.vicentehuidobro.uchile.cl/manifiesto1.htm

- Non serviam. http://www.vicentehuidobro.uchile.cl/manifiesto4.htm

Kukla, A. 2000. Social constructivism and the philosophy of Science. London: Routledge.

Moore, G. 1983. Prueba del mundo exterior. In: Defensa del sentido común y otros ensayos.

Buenos Aires: Orbis.

Nietzsche, F. 1990. Sobre Verdad y mentira en sentido extra moral. Madrid: Tecnos.

- 1997. La genealogía de la moral. Madrid: Alianza.

- 2000. La voluntad de Poder. Madrid: EDAF.

- 2014. La gaya ciencia. In: Obras Completas, Volumen III. Madrid: Tecnos.

- 2015. Fragmentos Póstumos (1885-1889). Madrid: Tecnos.

Pannenberg, W. 1971. What is truth? In: Basic Questions in Theology, vol II. Philadelphia: Fortress Press.

Plantinga, A. 2011. Where the conflict really lies. Science, Religion, and Naturalism. Oxford: Oxford University Press.

Putnam, H. 1981. Reason, Truth and History. Cambridge: Cambridge University Press.

Putnam, H. 1991. The many faces of realism. Chicago: Open Court.

Rorty, R. 1991. Contingencia, Ironía y Solidaridad. Barcelona: Paidós.

Searle, J. 1995. The Construction of Social Reality. New York: Free Press.

Smith, C. 2010. What is a person? Rethinking Humanity, Social life, and the Moral Good from the Person up. Chicago: University of Chicago Press.

Taylor, C. 1993. Engaged agency and background in Heidegger. In: Charles Guignon (ed.)

The Cambridge Companion to Heidegger. Cambridge University Press.

Principia 21(1): 77-98 (2017). 
Wachterhauser, B. 1994. Introduction: Is there Truth after Interpreation? In: B. Wactherhauser (ed.) Hermeneutics and Truth. Evanston: Norhtwestern University Press.

- 1994. Gadamer's Realism: The "belongingness" of Word and Reality. In: B. Wactherhauser (ed.) Hermeneutics and Truth. Evanston: Norhtwestern University Press.

- 2002. Getting it Right: Relativism, Realism, and Truth. In: Robert Dostal (ed.) The Cambridge Companion to Gadamer. Cambridge: Cambridge University Press.

Williams, B. 2002. Truth and Truthfulness. Princeton and Oxford: Princeton University Press.

Carlos Miguel Gómez

Escuela de Ciencias Humanas

Universidad del Rosario, Bogotá.

carlos.gomezr@urosario.edu.co

\section{Notas}

${ }^{1}$ Esta compatibilidad es afirmada explícitamente en, por ejemplo, Putnam 1991, p.17 y Searle 1995, p.155, p.161. Y ciertamente representa uno de los grandes temas de la hermenéutica filosófica de Gadamer (cf. 2007, p.331ss) a partir de Ser y Tiempo (cf. especialmente §32 y §44). Para un análisis detallado del realismo hermenéutico de Gadamer Cf. Wachterhauser 1994 y 2002. Recientemente Hubert Dreyfus y Charles Taylor le han dedicado su libro Retrieving Realism (2015).

${ }^{2}$ Sobre el desarrollo del pensamiento de Nietzsche y sus radicales transformaciones con respecto a la verdad, así como sobre las principales tendencias de interpretación de este asunto en el pensamiento contemporáneo, ver Clark 1990. Esta autora muestra cómo Nietzsche gradualmente abandona el presupuesto central de su crítica a la verdad en el ensayo de 1873, esto es, una teoría metafísica de la correspondencia y la idea de la "cosa en sí misma", lo cual torna absurda la crítica según la cual no tenemos acceso al mundo tal y como es, de modo que nuestro conocimiento es siempre una falsificación de la realidad (Cf. Williams 2002, pp.12-19). No obstante, es posible encontrar pasajes en la obra de madurez de Nietzsche que parecen resonar con las ideas de "Sobre verdad y mentira", lo cual, como ha sido constantemente señalado, genera tensiones y contradicciones internas en su pensamiento.

${ }^{3}$ A partir de esta "duda de Darwin", Alvin Plantinga ha desarrollado su famoso "Argumento Evolutivo contra el Naturalismo": si la teoría de la evolución es correcta y el naturalismo (la idea según la cual todo lo que existe se reduce a leyes y entidades naturales, sin que exista ninguna realidad divina) es verdadero, entonces la probabilidad de que nuestras facultades cognitivas sean confiables (de que hayan evolucionado para generar creencias verdaderas) es muy baja o inescrutable. Pues creencias falsas pueden ser evolutivamente exitosas y contribuir, en algunos casos incluso mejor que las verdaderas, a la sobrevivencia de la especie. Pero si esto es así, entonces la conjunción entre evolucionismo y naturalismo hace inevitable el escepticismo y presenta al que afirme esta conjunción un "refutador" (defeater), pues no tiene ya ninguna razón para afirmar la verdad de ninguna teoría, incluida la verdad de la teoría de la evolución que presupuso en primer lugar (cf. 2011, pp.307-350).

Principia 21(1): 77-98 (2017). 
${ }^{4}$ Por ejemplo, Heidegger 2009, §44, p.232: “¿Con respecto a qué concuerdan los términos relacionados en la adaequatio? (...) si la igualdad es imposible en razón de la falta de homogeneidad de ambos, ¿serán entonces (el intellectus y la res) quizás semejantes?"

${ }^{5}$ Incluso Rorty reconoce que Nietzsche "se expone(n) a la objeción de inconsistencia autorreferencial, es decir, de que declara(n) conocer lo que ellos [él] mismo(s) declara(n) que no es posible conocer" (1991, p.28, nota 2). Ciertamente, Nietzsche reconoce que "incluso esto es también interpretación" (cf. La Voluntad de poder fragmento 481) y se podría argüir que no hay que leer sus afirmaciones como descripciones del modo como son las cosas (es decir, como implicando una pretensión de verdad), sino más bien como otra "forma de hablar", como nuevas "metáforas" tan inventadas como todo lo demás, es decir, como un ejercicio de su voluntad (¿la de quién?) para "dar forma a las cosas como a uno le place" y favorecer la vida. De nuevo el callejón sin salida: en tanto que todo conflicto de interpretaciones es en últimas un conflicto de voluntades, el autoritarismo es el desenlace natural del nihilismo.

${ }^{6}$ Comentando el pensamiento de Nicolas de Cusa, Pannenberg señala que "Dios es la única presuposición a partir de la cual la concordancia entre el pensamiento humano con una realidad extrahumana puede ser explicado y garantizado" (1971, p.17). En el primer capítulo de La verdad y las formas jurídicas, Foucault reafirma esta intuición comentado el texto de Nietzsche 1873: “¿Qué aseguraba en la filosofía occidental que las cosas a conocer y el propio conocimiento estaban en relación de continuidad? (...) ¿Quién sino Dios garantizaba esto en la filosofía occidental? (...) Si no existe más relación entre el conocimiento y las cosas a conocer, si la relación entre éste y las cosas conocidas es arbitraria, relación de poder y violencia, la existencia de Dios en el centro del sistema de conocimiento ya no es más indispensable" (2011, p.24). En realidad, la cuestión debe ser planteada a la inversa: Dado que la existencia de Dios no está ya en el centro del sistema de conocimiento, no es posible pensar ya más una relación de continuidad entre el conocimiento y las cosas. Lo primero es un presupuesto y no una conclusión de lo segundo. También Rorty concuerda con la intuición: "Excluir la idea del lenguaje como representación (...) equivaldría a desdivinizar el mundo (...) Pues en la medida en que pensemos que «el mundo» designa algo que debemos respetar y con lo que nos hemos de enfrentar, algo semejante a una persona, insistiremos en que toda explicación filosófica de la verdad retiene la «intuición» de que el mundo está «ahí afuera»." (1991, p.41)

${ }^{7}$ Aún más, como me indicó Juan Pablo Gómez, las figuras que pueden ser vistas en la placa de arena corresponden a las gráficas que resultan de las ecuaciones que predicen cómo se comportan las ondas del mismo sonido de entrada (teniendo en cuenta las condiciones de frontera y las fuentes que generan el sonido). Una rápida visita a youtube buscando "Chaldni Patterns" o "Resonance experiments" es suficiente para ver el punto de mi argumento.

${ }^{8}$ Cf. Smith 2010, p.160 y Habermas 2002, pp.24ss, pp.40ss.

${ }^{9}$ En otro de los Manifiestos, titulado "Non serviam", el poeta creacionista grita: "No he de ser tu esclavo, madre Natura; seré tu amo (...) Yo tendré mis árboles que no serán como los tuyos, tendré mis montañas, tendré mis ríos (...) Y ya no podrás decirme: «ese árbol está mal, no me gusta ese cielo... los míos son mejores». Yo te responderé que mis cielos y mis árboles son los míos y no los tuyos y que no tienen por qué parecerse".

${ }^{10}$ Interesantemente, esta perspectiva sin perspectiva o punto de vista desde ningún lugar, que es una contradicción en los términos, no puede nunca ser descrito como "El punto de vista de Dios". Más bien, se trata de una idea de la inmediatez de lo real que hace imposible 
cualquier inteligibilidad, pues niega la estructura relacional básica del conocimiento. Esta forma de objetivismo que no reconoce el polo de la subjetividad, es tan incapaz de reconocer la alteridad como el "subjetivismo" radical que afirma que el polo de lo real es enteramente construido. Si hubiera un "punto de vista de Dios", este sería más bien la sumatoria o la captación simultanea de todas las perspectivas posibles, de todos los puntos de vista posibles, es decir, de todos los modos posibles de la relacionalidad consciente: "un punto del espacio en donde están todos los puntos"; "el lugar donde están, sin confundirse, todos los lugares del orbe, vistos desde todos los ángulos" (en todos los momentos del tiempo, por todos los observadores posibles); "una esfera cuyo centro está en todas partes y las circunferencia en ninguna." - las metáforas del Aleph que desesperaron a Borges (1997) y a los místicos.

${ }^{11}$ Con la excepción, evidentemente, de formas radicales de socio-constructivismo para las cuales la realidad entera es dependiente en el tercer sentido. No voy a repetir aquí las críticas a este tipo de posturas que conducen a un sinfín de inconsistencias y callejones sin salida. Cf. Kukla 2000; Bogossian 2006; Smith 2010; Elder-Vass 2012.

Principia 21(1): 77-98 (2017). 